\title{
Prevalence of Malaria Parasite among Asymptomatic Primary School Children in Angiama Community, Bayelsa State, Nigeria
}

\section{Abah $\mathrm{AE}^{1^{*}}$ and Temple $\mathrm{B}^{2}$}

${ }^{1}$ Department of Animal and Environmental Biology, Faculty of Science, University of Port Harcourt, PMB 5323 Port Harcourt 50001, Rivers State, Nigeria

${ }^{2}$ School of Science Laboratory Technology, University of Port Harcourt, PMB 5323, Port Harcourt, Nigeria

"Corresponding author: Austin Abah, Department of Animal and Environmental Biology, Faculty of Science, University of Port Harcourt, PMB 5323 Port Harcourt 50001, Rivers State, Nigeria, Tel: 234 8033402311; E-mail: austin.abah@uniport.edu.ng

Received date: November 25, 2015; Accepted date: December 14, 2015; Published date: December 17, 2015

Copyright: (C) 2015 Abah AE, et al. This is an open-access article distributed under the terms of the Creative Commons Attribution License, which permits unrestricted use, distribution and reproduction in any medium, provided the original author and source are credited.

\begin{abstract}
Study of prevalence of malaria parasite among asymptomatic primary school children was carried out in Angiama community, Southern ljaw local Government Area, Bayelsa state, Nigeria using the blood film staining method. A total of 300 samples were collected, stained with both Field stains A\&B and Giemsa stains and examined microscopically. Out of the 300 samples, 190 (63.3\%) were found to be positive with malaria parasite at varying degrees of parasiteamia. Sex related infection showed that more males $(56.8 \%)$ were infected than females $(43.2 \%)$, Age related infection showed that children within the ages of 4-6years were more infected (41.1\%) than children in other age range (7-9years $36.3 \%$ and $10-12$ years $22.6 \%$ ). Plasmodium falciparium species was found to be the cause of malaria in Angiama. Despite all the efforts to curb malaria infections, the prevalence rate in Angiama community remains very high and therefore necessitates a closer monitoring of the implementation of the policies targeted at malaria elimination.
\end{abstract}

Keywords: Malaria parasite; Prevalence; Primary school children; Angiama community; Bayelsa state; Nigeria

\section{Introduction}

Malaria is a life-threatening disease caused by parasites that are transmitted to people through the bites of infected female Anopheles mosquitoes. Almost half of the world's population is at risk of malaria. Current report by the world Health Organization shows that, globally, an estimated 3.3 billion people are at risk of being infected with malaria and developing disease [1].

Malaria is a major public health problem in Nigeria where it accounts for more cases and deaths than any other country in the world [2]. Malaria is a risk for $97 \%$ of Nigeria's population. The remaining $3 \%$ of the population live in the malaria free highlands. An estimated 100 million malaria cases and about 300,000 deaths each year make Nigeria the country with the highest number of malaria casualties worldwide [3].

In 2005, the World Health Assembly set as a target the reduction of malaria cases and deaths by $75 \%$ by 2015 . In 2011, the Roll Back Malaria (RBM) Partnership updated the objectives and targets and made it more ambitious to reduce deaths due to malaria to near zero by 2015 [4]. The WHO Global Technical Strategy for Malaria 2016-2030 which was adopted by the World Health Assembly in May 2015 provided a technical framework for all malaria-endemic countries. It is intended to guide and support regional and country programmes as they work towards malaria control and elimination [5].

Many researchers have reported very high prevalence of parasitaemia in Nigeria. Kalu et al. reported $80.40 \%$ in their comparative study of prevalence of malaria in Aba and Umuahia urban Areas of Abia state, Nigeria [6]. They also reported $93.30 \%$ and $80.30 \%$ in Aba and Umuahia respectively. Oparaocha reported $73.30 \%$ in
Ikwuano area of Abia State [7]. Ukpai and Ajoku reported $85.50 \%$ in Okigwe and $75.00 \%$ in Owerri in Imo State [8]. All these studies were conducted within the South Eastern Nigeria. Olasehinde et al. reported $80.50 \%$ in the prevalence study among infants and children in Ota, Ogun state, South Western Nigeria [9].

Niger Delta occupies a very low coastal plain with so many water bodies and malaria is endemic. Bayelsa State has a population of about 1.5 million inhabitants and malaria is the main cause of illness and death [10]. There are dearths of reports on malaria prevalence from this State. In order to achieve the set goal of the WHO, current status of malaria prevalence needs to be established. The aim of this study was to determine the prevalence of malaria parasite among asymptomatic school children in Angiama community, Bayelsa State.

\section{Materials and Methods}

\section{Study area}

Bayelsa State is located in the Niger Delta region, Southern Nigeria. Its capital is Yenagoa and it is bordered on the west by Rivers State, on the East and South by the Atlantic Ocean and on the North by Delta State. Angiama community is in Southern Ijaw Local Government Area (LGA) at $\mathrm{N} 4^{\circ} 52^{\prime \prime}$ and $\mathrm{E}^{\circ} 12^{\prime \prime}$. Rainfall in Bayelsa State varies in quantity from one area to another, The state experiences equatorial type of climate in the southern the most part and tropical rain towards the northern parts. Rain occurs generally every month of the year with heavy downpour. The mean monthly temperature is in the range of $25^{\circ} \mathrm{C}$ to $31^{\circ} \mathrm{C}$. Mean maximum monthly temperatures range from $26^{\circ} \mathrm{C}$ to $31^{\circ} \mathrm{C}$. The mean annual temperature is uniform for the entire Bayelsa State. The hottest months are December to April. The difference between the wet season and dry season temperatures is about $2^{\circ} \mathrm{C}$ at the most. Relative humidity is high in the state throughout the year and decreases slightly in the dry season. The 
Vegetation of the state is composed of four ecological zones. These include: Coastal barrier island forests, mangrove forests, freshwater swamp e.g. forests and lowland rain forests. These vegetation types are associated with the various soil units in the area. Much of the terrain is swampy and extensive areas of the land are flooded for most of the year.

\section{Sampling}

After informed consents were obtained from the parents and school authority, a total of 300 pupils (117 males and 183 females) were recruited for the study from three different schools namely

\section{St. Matthew's Primary School 1 N4 ${ }^{\circ} 54^{\prime \prime}$ and E6 $6^{\circ} 12$ \\ St. Matthew's Primary School 11 N4 $4^{\circ} 53$ and E6 12 " and \\ Community Primary School N4 54 and E6 ${ }^{\circ} 12^{\prime \prime \prime}$}

One hundred samples of venous blood were collected from pupil in each of the schools in anticoagulant (EDTA) and taken to the Parasitology Laboratory, University of Port Harcourt for analyses.

\section{Laboratory analyses}

Both thick and thin blood films were prepared, stained and examined following the method described by Cheesbrough [11]. Thick and thin blood films were made and labeled on a clean glass slide as recommended by World Health Organization (WHO). The thin films were fixed with methanol and all films were stained with 3\% Giemsa stain at $\mathrm{pH} 7.0$ for 30 minutes [12]. The blood films were examined under the microscope using the oil immersion (100x) objectives as described by Cheesbrough [11]. The Thick films were used to determine the parasite density while the thin film was used to differentiate the species of the parasites.

\section{Results}

Prevalence of malaria parasite in Angiama community indicated that out of 300 children examined, 190 (63.30\%) of them were infected with malaria parasite. The children within the ages of 4-6 years were more infected $(41.10 \%)$ than the children from the other age range, this was followed by those between $7-9$ years $(36.3 \%)$ and the list was $10-12$ years $(22.6 \%)$ (Figure 1 ).

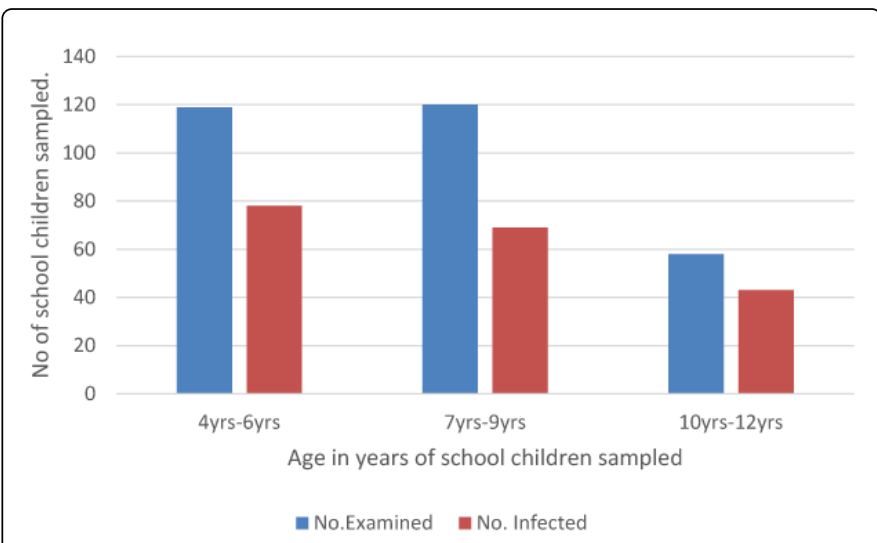

Figure 1: Prevalence of malaria parasite according to age.
Plasmodium falciparium is the only malaria species found to be the cause of malaria parasite infection in the study area. Sex related prevalence showed that more males 108 (56.8\%) were infected among the study populations than 82 (43.2\%) females (Figure 2).

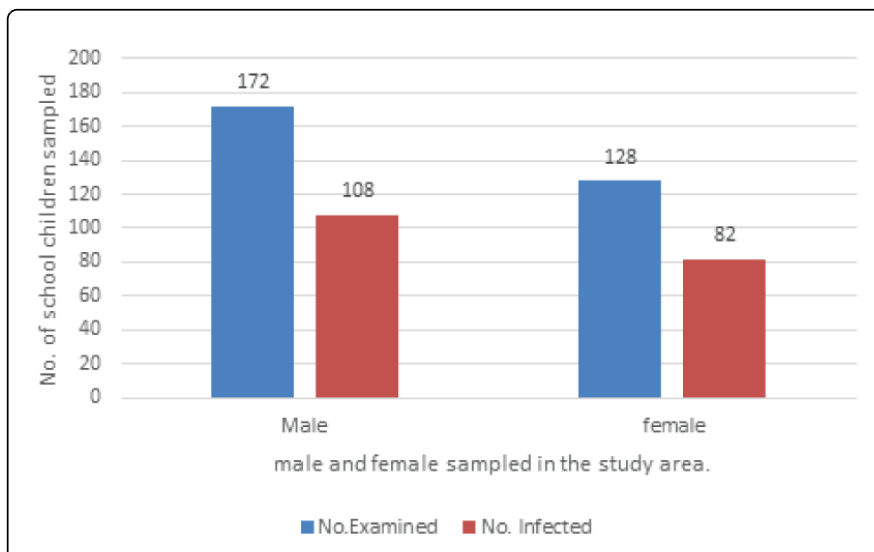

Figure 2: Sex related prevalence of malaria infections in the study area.

On the bases of their classroom arrangements, children in class 2 were more infected $(27.9 \%)$ followed by children in class $3(21.1 \%)$, class $4(14.7 \%)$, class $6(13.7 \%)$, class1 $(12.1 \%)$ and class $5(10.5 \%)$ the least infected.

\section{Discussion}

The prevalence of $63,30 \%$ of malaria parasite in the study area is considered high. This high prevalence has been reported in the southern zone of Nigeria by other researchers $[6-9,13,14]$ and confirms the endemicity of malaria in Nigeria and as having more cases than any other country in the sub-Saharan Africa [2]. Majority of previous works in the area dwelt on cases that were presented in hospitals and diagnostic centres $[9,13,14]$. The fact that these children reported to school without any sign of ailment or complaints makes it very significant.

The high prevalence of malaria in this community could be attributed to the environment which apart from being typical of the mangrove vegetation and tropical rain forest zone, is lower coastal plain with lots of water and encourages vector breeding since epidemiologic patterns of malaria infection are governed by environmental parameters that regulate vector populations of mosquitoes. Elsewhere, Bloland et al. had established that low density infections were not significantly associated with fever among children [15]. Inadequate treatment which limits parasite densities without eliminating them may actually increase the proportion of children with clinically silent malaria infections.

The age distribution showed that children within the age 4-6 were more infected than other age range. This finding corroborates the observations made by WHO; that the malaria burden is heavier in subSaharan Africa than other parts of the world where an estimated $90 \%$ of all deaths due to malaria occur, and children under 5 years, account for $78 \%$ of all deaths [5]. Children within the age range of 10-12 years were least infected. It appears that as they grow older, they become more careful with precautionary measures against the transmission of malaria parasite infections and are more likely to adhere to instructions of sleeping under the insecticide-treated nets (ITN). Apart 
Citation: Abah AE, Temple B (2015) Prevalence of Malaria Parasite among Asymptomatic Primary School Children in Angiama Community, Bayelsa State, Nigeria. Trop Med Surg 4: 203. doi:10.4172/2329-9088.1000203

Page 3 of 3

from these explanations, the progressive acquisition of immunity by older children as a result of subsequent exposures to malaria parasites as observed by Bloland et al. may explain this trend of observation [15].

The prevalence of species of malaria parasite shows that Plasimodium falciparium is the responsible for all the infections observed. This agrees with earlier observations by WHO that majority of infections in Africa are caused by Plasmodium falciparum, the most dangerous of the four human malaria parasites (the others being Plasmodium vivax, Plasmodium malariae and Plasmodium ovale).

\section{Conclusion}

This study has established that the prevalence of malaria parasite in Angiama community in Bayelsa State is still high and would require coordinated effort to reduce malaria deaths to near zero in the area even by 2030 . The main malaria intervention measures which comprise vector control (which reduces transmission by the mosquito vector from humans to mosquitoes and then back to humans), achieved using insecticide-treated mosquito nets (ITNs) or indoor residual spraying (IRS); chemoprevention (which prevents the blood stage infections in humans); and case management (which includes diagnosis and treatment of infections) are effective and affordable and require supervision and enforcement for the desired results of elimination of malaria not only in Angiama community in Bayelsa State but entire Nigeria and Africa.

\section{References}

1. WHO (2015) Malaria Fact Sheet No 94. World Health Organization Geneva 27, Switzerland.

2. CDC (Centre for Disease Control) (2012) Atlanta co 800-CDC-info. US Department and Health.

3. NMFS (Nigeria Malaria Fact Sheet) (2011). United States Embassy in Nigeria.
4. RBM (2008) The global malaria action plan. Geneva, Roll Back Malaria (RBM) Partnership, World Health Organization.

5. WHO (2014) World malaria report 2014. World Health Organization, 20 Avenue Appia, 1211 Geneva 27, Switzerland

6. Kalu Mong Kalu, Nwogo Ajuka Obasi, Florence Onyemachi Nduka, Glory Otuchristian (2012) A comparative study of the prevalence of Malaria in Aba and Umuahia urban areas of Abia State, Nigeria. Research Journal of Parasitology 7: 17-24.

7. Oparaocha ET (2003) The impact of heamoglobin level and concomitant infections on malaria parasitaemia and on-set of fever during malaria attack in Ikwuano local government area of Abia State, Nigeria. Nigerian Journal of Parasitology 24: 25-32.

8. Ukpai OM and Ajoku EI (2001) The prevalence of Malaria in Okigwe and Owerri areas of Imo State. Nigerian Journal of Parasitology 22: 43-48.

9. Olasehinde, GI, AA Ajayi, SO Taiwo, BT Adekeye and OA Adeyeba (2010) Prevalence and Management of Faciparium Malaria among infants and children in Ota, Ogun State, South western Nigeria. African Journal of Clinical and Experimental Microbiology 11: 159-163.

10. MSF (Medecins sans Frontiers) (2000) Fighting malaria in Niger Delta. International website of medecins Sans frontiers (msf). MSF USA 333 7th Avenue, New York, NY 10001-5004| 212-679-6800A 501(c) (3) taxexempt organization. Federal Identification Number (EIN):13-3433452

11. Cheesbrough, M (2006) District Laboratory Practice in Tropical Countries" 2nd Edition update Part 1. Cambridge University Press Edinburgh, UK. Pp 239-242.

12. WHO (2000) Malaria diagnosis, new perspectives. Geneva, World Health Organization.

13. Okafor HU, Oguonu $\mathrm{T}$ (2006) Epidemiology of malaria in infancy at Enugu, Nigeria. See comment in PubMed Commons below Niger J Clin Pract 9: 14-17.

14. Madukosiri CH, Bawo DS (2012) Illness pattern and the relationship between the Prevalence of malaria and other infections in Niger Delta University. Agriculture and Biology Journal of North America 2151-7525.

15. Bloland PB, Boriga DA, Ruebush TK, McCormick JB, Roberts JM, et al. (1999) Infection in an area of intense Malaria transmission II. Descriptive epidemiology of malaria infection and disease among children. American Journal of Tropical Medicine and Hygiene 60: 641-648. 